\title{
Clearance of refractory bile duct stones with extracorporeal shockwave lithotripsy
}

\author{
R D Ellis, A P Jenkins, R P H Thompson, R J Ede
}

\begin{abstract}
Background-Extracorporeal shockwave lithotripsy (ESWL) has been used since the mid-1980s to fragment bile duct stones which cannot be removed endoscopically. Early machines required general anaesthesia and immersion in a waterbath.

Aims-To investigate the effectiveness of the third generation Storz Modulith SL20 lithotriptor in fragmenting bile duct stones that could not be cleared by mechanical lithotripsy.

Methods-Eighty three patients with retained bile duct stones were treated. All patients received intravenous benzodiazepine sedation and pethidine analgesia. Stones were targeted by fluoroscopy following injection of contrast via a nasobiliary drain or $\mathbf{T}$ tube. Residual fragments were cleared at endoscopic retrograde cholangiopancreatography.

Results-Complete stone clearance was achieved in $69(83 \%)$ patients and in 18 of 24 patients $(75 \%)$ who required more than one ESWL treatment. Stone clearance was achieved in all nine patients $(100 \%)$ with intrahepatic stones and also in nine patients $(100 \%)$ referred following surgical exploration of the bile duct. Complications included six cases of cholangitis and one perinephric haematoma which resolved spontaneously.

Conclusion-Using the Storz Modulith, $83 \%$ of refractory bile duct calculi were cleared with a low rate of complications. These results confirm that ESWL is an excellent alternative to surgery in those patients in whom endoscopic techniques have failed.
\end{abstract}

(Gut 2000;47:728-731)

Keywords: lithotripsy; bile duct calculi; extracorporeal lithotripsy

Bile duct stones can be removed endoscopically with or without mechanical lithotripsy in over $90 \%$ of cases but such extraction can fail if the stones are large or the anatomy difficult. Immediate endoscopic drainage and a reduction in morbidity can also be achieved by insertion of a pigtail endoprosthesis or nasobiliary drain. While an endoprosthesis can be a definitive treatment in the elderly, bile duct clearance should be the goal for the majority. The relatively high mortality and morbidity of bile duct surgery ${ }^{1}$ has driven the search for less invasive techniques to remove these refractory stones, which have included $\mathrm{T}$ tube extraction, ${ }^{2}$ percutaneous transhepatic removal, ${ }^{3}$ chemical dissolution, ${ }^{4}$ laser lithotripsy, ${ }^{5}$ and electrohydraulic lithotripsy. ${ }^{6}$

Extracorporeal shockwave lithotripsy (ESWL) was first used to treat bile duct stones in $1985,{ }^{7}$ after its success and safety in treating renal calculi had been well established. ${ }^{8}$ Initial reports of successful stone clearance following ESWL used first generation lithotriptors (usually electrohydraulic, Dornier HM3 machine) that required immersion in a waterbath, usually under general anaesthesia. Second generation lithotriptors (usually electromagnetic Lithostar; Siemens or Piezolith 2300; Wolf) required only intravenous sedation and analgesia, and did not require immersion but generally achieved lower stone clearance rates. ${ }^{9-16}$

Here, we describe the experience of a single operator using a more powerful third generation lithotriptor, the Storz Modulith SL 20 lithotriptor.

Patients and methods

Between July 1990 and April 1996, 83 patients with bile duct stones that could not be cleared by endoscopic sphincterotomy and mechanical lithotripsy by experienced endoscopists underwent ESWL by a single operator (RJE) using the Storz Modulith SL 20 electromagnetic lithotriptor. Patients were treated in the supine position and the stones were targeted by biplanar fluoroscopy following insertion of a nasobiliary drain (70 cases) to enable contrast localisation or following surgical placement of a $\mathrm{T}$ tube (13 cases).

The Storz Modulith SL 20 lithotriptor produces shockwaves by electromagnetic induction, which are focused by an ellipsoidal reflector through a water cushion and hydrophilic gel on the skin on to the target. The wide aperture angle of $83^{\circ}$ enables precise focusing (focal volume $6 \mathrm{~mm}$ lateral and $30 \mathrm{~mm}$ axial) and permits anaesthesia free treatment.

All patients received intravenous benzodiazepine sedation with Diazemuls (mean $9 \mathrm{mg}$ ) and pethidine analgesia (mean $85 \mathrm{mg}$ ). Supplemental nasal oxygen was administered at $2-4$ $1 /$ min and patients were monitored by continuous electrocardiography (ECG) and pulse oximetry. Shockwaves were delivered at a rate of 2 per second but if frequent ventricular ectopy occurred the shock waves were ECG linked to avoid coincidence with ventricular depolarisation.

After lithotripsy, the nasobiliary drain was removed and endoscopic retrograde cholangio-

Abbreviations used in this paper: ESWL, extracorporeal shockwave lithotripsy; ERCP, endoscopic retrograde cholangiopancreatography; ECG, electrocardiogram. 
Table 1 Patient characteristics $(n=83)$

\begin{tabular}{lll}
\hline Characteristic & No of patients & $\%$ of patients \\
\hline Male & 30 & 36 \\
Age (y) & $68(15.3)^{\star}$ & \\
Previous cholecystectomy & 38 & 46 \\
T tube in situ & 13 & 16 \\
Previous surgical exploration of & 9 & 11 \\
$\quad$ duct & 9 & \\
Intrahepatic stones & $1.5(1.1)^{\star}$ & \\
Size of largest stone (cm) & & \\
No of stones & 38 & 46 \\
$\quad 1$ & 16 & 19 \\
2 & 12 & 14 \\
3 & 17 & 21 \\
$>3$ & &
\end{tabular}

Table 2 Number of extracorporeal shockwave lithotripsy (ESWL) sessions

\begin{tabular}{lcc}
\hline No of ESWL sessions & No of patients & No cleared (\%) \\
\hline 1 & 59 & $51(86)$ \\
2 & 21 & $16(76)$ \\
3 & 2 & $1(50)$ \\
4 & 1 & $1(100)$ \\
\hline
\end{tabular}

pancreatography (ERCP) was performed, usually on the same day. Surgically placed $T$ tubes were also removed at follow up ERCP provided satisfactory fragmentation had occurred. Any remaining fragments were removed by balloon trawling, basket retrieval, and mechanical lithotripsy (Olympus, BML-3Q-1).

All patients had prior routine haematological (including platelet count and prothrombin time) and biochemical investigations. Pyrexia and cholangitis were treated with intravenous antibiotics before ESWL was performed.

Thirty men and 53 women with a mean age of 68 years were treated. Thirty eight $(46 \%)$ had undergone previous cholecystectomy. The characteristics of the patients and stones are shown in table 1.

\section{Results}

LITHOTRIPSY

A total of 111 ESWL sessions were performed in 83 patients (mean 1.3 (SD 0.6)) (table 2). Mean shocks per session was 3913 (1530) at a mean power of $15.0 \mathrm{kV}$ (2.9).

ERCP

A mean of 1.5 (0.8) ERCPs were performed following insertion of the nasobiliary drain or $\mathrm{T}$ tube until either duct clearance was achieved or attempts at ESWL were abandoned. A mean of 1.2 ERCPs were performed in 14 patients not successfully cleared of stones, compared with 1.6 in 69 patients whose ducts were cleared. This difference was not statistically significant and reflects the fact that three day case referrals from other hospitals did not have post-ESWL ERCPs, presumably because insufficient fragmentation had occurred and all three cases underwent surgery.

CLEARANCE

Complete duct clearance was achieved in 69 of 83 patients $(83 \%)$. Eighteen of 24 patients $(75 \%)$ requiring more than one session of ESWL were cleared. The duct was successfully cleared in all nine patients with intrahepatic stones and only one of these patients required two ESWL sessions.

Of the 14 patients who were not successfully cleared, five underwent surgical exploration of the duct, while nine were stented endoscopically without further attempts to remove the stones (seven because of advanced age; one coexistent metastatic carcinoma of the gall bladder; one cast-like, complex calculus).

Nine patients had been referred following surgical exploration of the bile duct at cholecystectomy with subsequent failed endoscopic attempts at removal of stones; all were successfully cleared following ESWL.

\section{COMPLICATIONS}

Six patients (four successful; two not cleared) developed cholangitis after ESWL and subsequent ERCP. Two patients developed low grade fever and one developed a fever associated with a possible biliary leak resulting from ERCP; all were treated successfully with intravenous antibiotics. One patient developed a right perinephric haematoma that resolved spontaneously and one patient had transient macroscopic haematuria.

There was one death within 30 days of ESWL: an 81 year old woman with hypertrophic cardiomyopathy and cardiac failure died six days after ESWL from cardiac failure.

\section{STATISTICAL ANALYSIS}

Clinical data known prior to ESWL (age, sex, body weight, number of stones, diameter of largest stone, presence of intrahepatic stones, previous cholecystectomy, previous surgical exploration of the bile duct, and presence of " $T$ tube") and data from the treatments themselves (number of ESWL sessions, number, power and targeting of shocks, dose of Diazemuls and pethidine, total number of ERCPs, method of endoscopic extraction, occurrence of complications) were analysed by neural network analysis (4thought) to determine their influence on successful clearance. The analysis was based on structuring the data into successive ESWL sessions.

Initially, linear models were constructed to test the impact of variables when younger age and smaller diameter of the largest stone were found to be the strongest determinants of successful clearance following the first ESWL sessions ( $\mathrm{f}=11.5$, effective root mean squared $\mathrm{p}$ value 0.02 and 0.02 , respectively; effective $t$ statistic -2.45 and -2.8 , respectively). Thus the probability of successful clearance was reduced by $8 \%$ for every additional 10 years of age, and by $14 \%$ for every $1 \mathrm{~cm}$ increase in diameter of the largest stone. In this model, the sex of the patient appeared to influence successful clearance, with females cleared more easily, but was a weaker influence than age and diameter of the stone. Thus when the effect of sex was removed by analysing males and females separately, in males ( $\mathrm{f}=5.1$ ), the effect of age $(p=0.11, t=-1.64)$ and diameter of the largest stone $(\mathrm{p}=0.19, t=-1.6)$ was greater than in females $(\mathrm{f}=7.4 ; \mathrm{p}=0.13, t=-1.56$ for age, and $\mathrm{p}=0.14$ and $t=-1.8$ for diameter of the largest 
Table 3 Published series of extracorporeal shockwave lithotripsy (ESWL) of bile duct stones (>20 patients)

\begin{tabular}{|c|c|c|c|c|c|c|c|c|}
\hline Study & \multicolumn{2}{|c|}{$\begin{array}{l}\text { No of } \\
\text { patients }\end{array}$} & Lithotriptor & Anaesthesia & Visualisation & $\begin{array}{l}\text { Fragmentation } \\
\text { rate }(\%)\end{array}$ & $\begin{array}{l}\text { Clearance } \\
\text { rate }(\%)\end{array}$ & $\begin{array}{l}\text { No of } \\
\text { deaths }\end{array}$ \\
\hline $\begin{array}{l}\text { Sauerbruch } \\
\text { multicentre }^{17}\end{array}$ & \multicolumn{2}{|l|}{113} & EH Dornier HM3 & Mostly GA & $X$ ray & 91 & 86 & 2 \\
\hline $\begin{array}{l}\text { Sauerbruch } \\
\text { single centre }\end{array}$ & \multicolumn{2}{|l|}{103} & EH Dornier HM3 & Mostly GA & $X$ ray & 92 & 88 & 1 \\
\hline Moody $^{18}$ & \multicolumn{2}{|l|}{56} & EH Dornier HM3 & AS & $X$ ray & 91 & 75 & 0 \\
\hline Wenzel $^{19}$ & \multicolumn{2}{|l|}{55} & EH Dornier HM3 & Mostly GA & $X$ ray & - & 92 & 0 \\
\hline Lindstrom $^{20}$ & \multicolumn{2}{|l|}{37} & EH Dornier HM3 & AS & $X$ ray & - & 89 & - \\
\hline Van der Hul ${ }^{21}$ & \multirow{2}{*}{\multicolumn{2}{|c|}{$\begin{array}{l}77 \\
13\end{array}$}} & EH Dornier HM3 & $\begin{array}{l}\text { AS } \\
\text { GA }\end{array}$ & $X$ ray & 85 & 69 & 0 \\
\hline Schulz $^{10}$ & & & EM Lithostar & AS & $X$ ray & - & 69 & 0 \\
\hline $\mathrm{Lee}^{9}$ & 70 & $\begin{array}{l}62 \\
8\end{array}$ & $\begin{array}{l}\text { EM Lithostar } \\
\text { EH Dornier HM3 }\end{array}$ & AS & $X$ ray & - & 61 & 1 \\
\hline Nicholson $^{11}$ & 54 & & EM Lithostar & AS & $X$ ray & 81 & 70 & 1 \\
\hline Dobrilla $^{12}$ & 49 & & EM Lithostar & AS & $X$ ray & 94 & 88 & 0 \\
\hline \multirow[t]{2}{*}{ den Toom ${ }^{13}$} & \multirow[t]{2}{*}{62} & 49 & EM Lithostar & AS & $X$ ray & 86 & 73 & \\
\hline & & 13 & EH Dornier HM3 & GA & & 100 & 100 & \\
\hline Staritz $^{14}$ & 33 & & EM Lithostar & AS & $X$ ray & - & 64 & 0 \\
\hline Ginestal-Cruz $^{15}$ & 30 & & EM Lithostar & AS & $X$ ray & - & 80 & 2 \\
\hline Weiss $^{16}$ & 32 & & $\mathrm{PZ}$ & AS & Ultrasound & - & 75 & - \\
\hline
\end{tabular}

GA, general anaesthetic; AS, analgesia and/or intravenous sedation; EH, electrohydraulic; EM, electromagnetic; PZ, piezolith.

stone), with the effect of 10 years additional age being a reduction in probability of successful clearance of $10 \%$ and $6 \%$ for males and females, respectively, and of an additional $1 \mathrm{~cm}$ in diameter of the largest stone of $16 \%$ and $10 \%$, respectively.

Furthermore, when body weight was added to the linear model, a small effect was observed: in males ( $\mathrm{f}=1.7)$, an increase of $10 \mathrm{~kg}$ in weight reduced the probability of clearance by $3.5 \%$ $(\mathrm{p}=0.66, t=0.45)$, an additional 10 years in age by $9 \%(\mathrm{p}=0.23, t=-1.2)$, and $1 \mathrm{~cm}$ increase in diameter of the largest stone by $13 \%(\mathrm{p}=0.27$, $t=-1.2)$; in females $(\mathrm{f}=2.2)$, the equivalent effects were $6 \%(p=0.32, t=1.1), 7 \%(p=0.17$, $t=-1.5)$ and $7 \%(\mathrm{p}=0.35, t=-1.1)$, respectively.

Thus lighter weight and female sex may be associated with increased probability of successful clearance, but the associations fell short of conventional statistical significance and further larger studies are required to confirm these effects.

\section{Discussion}

Previous studies have reported success in treating retained bile duct stones with ESWL. First generation lithotriptors (for example, Dornier HM3) achieved higher clearance rates than second generation machines (mean clearance rate $83 \%$ versus $72 \%$, respectively) (table 3 ) but required the patient to be immersed in a waterbath. Furthermore, the higher energy shocks delivered by first generation machines necessitated either general or spinal anaesthesia, which are best avoided in the generally elderly population that is referred for bile duct ESWL. In this study, using the latest generation Storz Modulith SL 20 extracorporeal lithotriptor, stone clearance was achieved in $83 \%$ of patients with retained bile duct stones that could not be removed by endoscopic mechanical lithotripsy. These results are thus comparable with those obtained using first generation machines, but without the need for immersion or general anaesthesia. This reduction in analgesic requirement is probably related to the highly focused nature of the shockwaves generated by the Storz Modulith, which enter the patient over a correspondingly larger surface area than earlier machines.

The results of the present study are all the more impressive since this was a highly selected group of patients in whom other techniques, including mechanical lithotripsy or surgical attempts at extraction (nine cases), had failed because of large stone size, stone impaction, or inaccessibility due to abnormal anatomy. The clearance rate of $83 \%$ achieved after a mean of only 1.3 ESWL sessions indicates that this is a highly effective treatment for this difficult group of patients and compares favourably with the mean stone clearance rate of $66 \%$ achieved in 11 studies using analgo-sedation (table 3). None of these earlier reports used the Storz Modulith or included as many patients (mean 49 cases) as in the present study. Clearly there are important differences between the various extracorporeal lithotriptors that need to be considered when interpreting the results.

In accordance with previous reports, complication rates were low with only six cases of cholangitis, all rapidly and successfully treated with antibiotics, one spontaneously resolving perinephric haematoma, and a single unrelated death that occurred later from other causes. Perinephric haematoma is a well recognised complication of renal stone lithotripsy and invariably resolves spontaneously within 2-3 weeks without sequelae.

In the 24 patients whose stones were not cleared after the first session of ESWL, further treatment sessions resulted in an eventual overall clearance rate of $75 \%$, confirming that repeated treatment with ESWL is worthwhile. Many of our patients were referred from other hospitals for treatment as day cases, and this probably explains why only three patients underwent more than two ESWL treatments. It is likely that a higher clearance rate could have been achieved with additional treatment sessions. Thus in nine cases the referring physician/surgeon did not consider further ESWL treatment appropriate and these elderly cases were then left with long term pigtail stents in situ. A further three cases underwent 
surgery after only one ESWL treatment. While surgical exploration also enables the gall bladder to be removed, in older less fit patients ESWL can be used to treat symptomatic gall bladder stones, although repeated treatments may be necessary.

It is of interest that all nine patients referred following unsuccessful surgical clearance of the bile duct at the time of cholecystectomy were successfully cleared by ESWL.

Patients with intrahepatic calculi pose a particular challenge in that selective cannulation of the appropriate intrahepatic duct using a stone retrieval basket at ERCP can be difficult and it may not be possible to advance the basket beyond the stone. Previous studies have reported clearance rates varying from $40 \%$ (two of five patients) ${ }^{9}$ to $67 \%$ (six of nine) ${ }^{20}$ in patients with intrahepatic stones treated with ESWL. In this study, stone clearance was achieved in all nine cases with intrahepatic stones.

Neural network analysis indicated that the most important determinants of successful clearance were patient age, sex, and size of the stones. We did not routinely measure stone density by computerised tomography but none of the stones that we failed to clear showed calcification on plain $x$ ray. The better stone clearance rate observed in younger patients may be related in part to slight differences in skin water content and collagen deposition associated with aging, which could alter the acoustic impedance of the skin in elderly patients. A more likely explanation may be the increase in subcutaneous fat deposition in the elderly which may attenuate the shockwaves as acoustic velocity in fat is known to be lower than in muscle. ${ }^{22}$

In conclusion, bile duct clearance was achieved in $83 \%$ of cases using the Storz Modulith SL 20 lithotriptor. This treatment was associated with a low complication rate and confirms that ESWL is an excellent alternative to surgery in this group of patients when endoscopic techniques have failed.

We would like to thank those doctors who referred patients for extracorporeal lithotripsy and the many junior doctors who helped to look after them. We also thank the staff of the lithotripsy unit for their support. RDE and APJ were supported by the Special Trustees for St Thomas' Hospital.
1 Vellacott KD, Powell PH. Exploration of the common bile duct: a comparative study. Br F Surg 1979;66:389-91.

2 Burhenne HJ. Percutaneous extraction of retained biliary tract stones. AfR Am $\mathcal{F}$ Roentgenol 1980;134:888-98.

3 Clouse ME, Stokes KR, Lee RGL, et al. Bile duct stones: percutaneous transhepatic removal. Radiology 1986;160: 525-9.

4 Neoptolemos JP, Hofmann AF, Moossa AR. Chemical treatment of stones in the biliary tree. $\mathrm{Br} \neq \mathrm{f}$ Surg 1986;73:515-24.

5 Cotton PB, Kozarek RA, Schapiro RH. Endoscopic laser lithotripsy of large bile duct stones. Gastroenterology 1990;99:1128-33.

6 Bruckner M, Grimm H, Soehendra N. Electrohydraulic lithotripsy of complicated choledocholithiasis. Endoscopy 1990;22:234-5.

7 Sauerbruch T, Holl J, Sackmann M, et al. Fragmentation of bile duct stones by extracorporeal shock-wave lithotripsy: a five-year experience. Hepatology 1992;15:208-14.

8 Chaussey C, Schmiedt E, Jocham D, et al. Extracorporeal shockwave lithotripsy for treatment of urolithiasis. Urology 1984;23:59-66.

9 Lee SH, Fache JS, Burhenne HJ. The value of extracorporeal shock-wave lithotripsy in the management of bile duct stones. AfR Am f Roentgenol 1990;155:775-9.

10 Schulz HJ, Brien G, Kunz B, et al. Extrakorporale Stosswellenlithotripsie der Cholodocholithiasis. Z Klin Med 1989;44:2349-50

11 Nicholson DA, Martin DF, Tweedle DE, et al. Management of common bile duct stones using a second-generation extracorporeal shockwave lithotriptor. Br f Surg 1992;79: 811-14.

12 Dobrilla G, de Pretis G, Felder M, et al. Extracorporeal shock-wave lithotripsy in bile duct stones refractory to papillosphincterotomy. Eurf Gastroenterol Hepatol 1992;4:475-

13 den Toom R, Nijs HGT, van Blankenstein $M$, et al. Extracorporeal shock wave treatment of common bile duct stones: experience with two different lithotriptors at a single institution. Br F Surg 1991;78:809-13.

4 Staritz M, Rambow A, Grosse A, et al. Electromagnetically generated extracorporeal shockwaves for fragmentation of extra- and intrahepatic bile duct stones: indications, success and problems during a 15 months clinical experience. Gut 1990;31:222-5.

15 Ginestal-Cruz A, Grima M, Duarte V, et al. Extracorporeal shock wave lithotripsy for large common bile duct stones: an extension of the endoscopic approach. F Lithotripsy Stone Dis $1989 ; 1: 272-81$.

16 Weiss W, Turk C, Brownstone E, et al. Klinische Relevanz der extrakorporalen Stosswellenlithotripsie bei Choledocholithiasis. Wien Klin Wochensch 1989;101:629-31.

17 Sauerbruch T, Stern M. Fragmentation of bile duct stones by extracorporeal shock waves. Gastroenterology 1989;96: $146-52$.

18 Moody FG, Amerson JR, Berci G, et al. Lithotripsy for bile duct stones. Am F Surg 1989;158:241-7.

19 Wenzel H, Greiner L, Jakobeit C, et al. Extrakorporalle Stosswellenlithotripsie von Gallengangssteinen. Dtsch Med Wochenschr 1989;114:738-43.

20 Lindstrom E, Borch K, Kullman EP, et al. Extracorporeal shock wave lithotripsy of bile duct stones: a single institution experience. Gut 1992;33:1416-20.

21 van der Hul RL, Plaisier PW, van Blankenstein M, et al. Extracorporeal shock wave lithotripsy of common bile duct stones in patients with increased operative risk. Eur $\mathcal{F}$ Surg 1994;160:31-5.

22 Miles CA, Fursey GAJ, York PWR. New equipment for measuring the speed of ultrasound and its application in the estimation of body composition of farm livestock. In: Lister D, ed. In vivo measurement of body composition in meat animals. London: Elsevier Applied Science, 1994:93-105. 